\title{
A LEADER in the management of type 2 diabetes and \\ cardiorenal disease
}

\author{
Subodh Verma, MD, PhD, ${ }^{\mathrm{a}, \mathrm{b}, \mathrm{c}}$ Lawrence A. Leiter, MD, ${ }^{\mathrm{d}, \mathrm{e}, \mathrm{f}}$ David A. Latter, MD, ${ }^{\mathrm{a}, \mathrm{b}}$ and \\ Deepak L. Bhatt, MD, MPH ${ }^{\mathrm{g}}$
}

\footnotetext{
From the ${ }^{\mathrm{a}}$ Divisions of Cardiac Surgery and ${ }^{\mathrm{d}}$ Endocrinology and Metabolism, Li Ka Shing Knowledge Institute of St Michael's Hospital, Toronto, Ontario, Canada; Departments of ${ }^{\mathrm{b}}$ Surgery, ${ }^{\mathrm{c}}$ Pharmacology and Toxicology, ${ }^{\mathrm{e}}$ Medicine, and ${ }^{\mathrm{f}}$ Nutritional Sciences, University of Toronto, Toronto, Ontario, Canada; and ${ }^{\mathrm{g}}$ Brigham and Women's Hospital Heart \& Vascular Center, Harvard Medical School, Boston, Mass.

Received for publication Feb 12, 2019; revisions received March 10, 2019; accepted for publication March 17, 2019; available ahead of print June 19, 2019.

Address for reprints: Subodh Verma, MD, PhD, Division of Cardiac Surgery, 8th Floor, Bond Wing, St Michael's Hospital, 30 Bond St, Toronto, Ontario, M5B 1W8 (E-mail: vermasu@smh.ca).

J Thorac Cardiovasc Surg 2020;159:978-84

$0022-5223 / \$ 36.00$

Copyright (c) 2019 Published by Elsevier Inc. on behalf of The American Association for Thoracic Surgery https://doi.org/10.1016/j.jtcvs.2019.03.134
}

\section{THE SCOPE OF THE PROBLEM}

It is currently estimated that globally approximately 1 in 11 adults have type 2 diabetes, and it is expected that approximately 650 million individuals will have the disorder by $2045 .{ }^{1}$ However, this may represent the tip of the iceberg, since a large proportion of patients have prediabetes and undiagnosed diabetes.

Diabetes portends a poor prognosis primarily due to the marked acceleration of cardiovascular and renal complications. Indeed, diabetes is associated with profound increases in pipe, pump, and filter complications, which are manifested through increased atherosclerotic vascular events, heart failure, and progressive renal decline. ${ }^{2}$ Recent data from the Swedish National Diabetes Register remind us that the gradient of excess risk for all-cause mortality is widening in patients with diabetes compared with those without diabetes ${ }^{3}$ and data from the United States suggest that the rates of renal disease have not declined at the same rate as those of ischemic events in diabetes. ${ }^{4}$ Contemporary data remind us that there is a spectrum of risk in patients with diabetes and that the presence of polyvascular disease (ie, atherosclerosis involving more than one vascular bed, such as coronary, cerebrovascular or peripheral artery disease) substantially increases cardiovascular disease. ${ }^{5}$ In fact, Bonaca and colleagues, ${ }^{6}$ in a recent analysis of the IMProved Reduction of Outcomes: Vytorin Efficacy International (IMPROVE-IT) trial, identified the malignant cardiovascular phenotype observed in patients with type 2 diabetes, polyvascular disease, and a recent acute coronary syndrome. Although progress has been made in reducing the risk of vascular events in type 2 diabetes, rates of heart failure in patients with diabetes have remained a recalcitrant problem for which we have had little in the way of therapies before the advent of the sodium glucose cotransporter-2 (SGLT2) inhibitors. $^{7,8}$

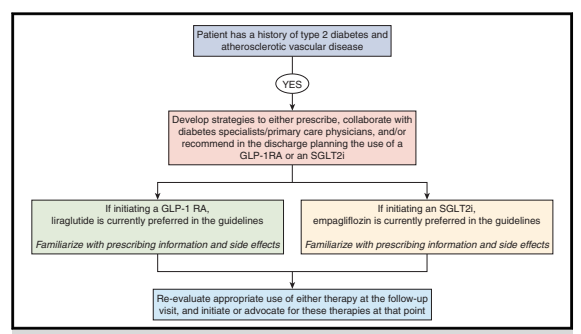

Approach to managing patients with cardiovascular disease and type 2 diabetes by the cardiac surgeon.

Central Message
Cardiac surgeons need to become familiar with
the current landscape of antihyperglycemic
therapies, particularly those that have been
shown to reduce cardiovascular events and
mortality.

The Invited Expert Opinion provides a perspective on this topic based on the following paper: Circulation. 2018;138:2884-2894. https://doi. org/10.1161/CIRCULATIONAHA.118.034516.

See Commentary on page 985 .
Declining renal function in patients with type 2 diabetes, although expected in many, is the leading cause of end-stage renal disease and dialysis dependency in North America. In addition to progressive renal decline, individuals with a reduced estimated glomerular filtration rate (eGFR), with or without evidence of albuminuria, are at a heightened risk for cardiovascular complications. Recent trials of patients with type 2 diabetes have reiterated the substantial step-up in risk of myocardial infarction (MI) and heart failure with worsening renal function. ${ }^{9}$ From a pathophysiologic stance, deteriorating renal function is associated with changes in hemodynamics, neurohumoral activation, inflammation, and acid-base homeostasis that tend to accentuate the risk of both atherosclerotic events and heart failure. ${ }^{10}$

In summary, the burden of diabetes-related cardiorenal complications continues to lower life expectancy and create economic challenges for both high-income and low-income countries. Accordingly, there is a pressing need for timely and effective interventions to prevent the onset and progression of these diabetes-associated comorbidities. 
The purpose of this editorial commentary is to discuss the Liraglutide Effect and Action in Diabetes: Evaluation of Cardiovascular Outcome Results (LEADER) trial, and specifically a recent post hoc analysis in patients with and without evidence of chronic kidney disease, with an emphasis on the clinical implications for cardiac surgeons.

\section{THE ADVENT OF THE US FOOD \& DRUG ADMINISTRATION-MANDATED CARDIOVASCULAR OUTCOME TRIALS IN DIABETES}

In 2008, the US Food \& Drug Administration issued a specific guidance indicating that all new antihyperglycemic agents must demonstrate cardiovascular safety. ${ }^{11}$ This mandate was based on the general paucity of data regarding the cardiovascular effects, whether harmful or efficacious, of antihyperglycemic agents that were available at that point in time. In fact, a meta-analysis of specific antihyperglycemic agents, such as rosiglitazone, raised concerns about the cardiovascular safety of antihyperglycemic drugs in general. ${ }^{12}$ Similar cumulative analysis of intensive glucose-lowering strategies also questioned the utility of antihyperglycemic agents on cardiovascular events, ${ }^{13}$ further underscoring the need for large cardiovascular trials of new glucose-lowering agents.

Subsequent to the new guidance, 4 large trials of dipeptidyl peptidase-4 (DPP-4) inhibitors have reported (Table 1). ${ }^{14-25}$ These trials studied patients with type 2 diabetes who primarily had established atherosclerotic vascular disease, although some of the trials also included individuals who had cardiovascular risk factors but did not have established cardiovascular disease. Individually and collectively, these trials demonstrated safety (but not superiority) of the DPP-4 inhibitors for the outcome of major adverse cardiovascular events (MACE), with one of the trials demonstrating an increase in heart failure hospitalizations with saxagliptin.

Three large trials of SGLT2 inhibitors have also been completed in patients with type 2 diabetes with either established vascular disease or with multiple risk factors (but without previous ischemic events) (Table 1). ${ }^{23-25}$ These trials not only demonstrated safety for MACE but also reported superiority (relative to placebo) with respect to cardiovascular death, reduction in heart failure hospitalizations, and renal preservation. A meta-analysis of these 3 trials showed considerable consistency in the benefit of canagliflozin, dapagliflozin, and empagliflozin with respect to the outcomes of heart failure and renal disease across a broad spectrum of both primary and secondary prevention populations, including those with a previous history of coronary artery bypass graft (CABG) surgery and peripheral artery disease. ${ }^{26-28}$ Resultantly, SGLT2 inhibitors (as well as glucagon-like peptide-1 receptor agonists [GLP-1RAs], as outlined to follow) are widely endorsed by clinical practice guidelines as preferred agents to be used in patients with type 2 diabetes who have clinical cardiovascular disease. ${ }^{29,30}$ Although much has been written about the mechanisms of cardiorenal protection with these agents with an emphasis of the natriuretic effects of the drugs, recent data also point toward the potential of cardiac reverse remodeling (as evaluated by left ventricular mass regression by cardiac magnetic resonance imaging) and potential changes in myocardial energetics. ${ }^{31-33}$

\section{THE GLP-1RA TRIALS: LEADER IN PERSPECTIVE}

The GLP-1RAs have been studied in 5 large cardiovascular outcome trials involving patients with type 2 diabetes who had a history of an acute coronary syndrome, established vascular disease, or multiple risk factors (Table 1). ${ }^{18,20-22,34}$ The specific agents studied have included lixisenatide, liraglutide, semaglutide, onceweekly exenatide, and albiglutide. As with the DPP-4 inhibitors and SGLT2 inhibitors, the cardiovascular outcome trials with GLP-1RAs that have reported to date compared the GLP-1RAs against placebo. No head-to-head comparison studies have been reported for any of the 3 classes of antihyperglycemic agents. Although lixisenatide and exenatide demonstrated cardiovascular safety (but not superiority to placebo), liraglutide, semaglutide, and albiglutide (which is not currently marketed) all demonstrated cardiovascular efficacy.

The LEADER trial was a double-blind randomized trial of 9340 patients with type 2 diabetes. Participants were randomized to receive either liraglutide $1.8 \mathrm{mg}$ per day (or maximum tolerated dose) or placebo (administered subcutaneously) in addition to standard of care with a median follow-up period of 3.8 years. ${ }^{21}$ The inclusion criteria were a hemoglobin A1c greater than $7.0 \%$; age 50 years or older, at least one coexisting cardiovascular condition (coronary heart disease, cerebrovascular disease, peripheral artery disease, stage 3 or more advanced chronic kidney disease, or chronic heart failure of New York Heart Association class II or III); or age 60 years or older with at least 1 additional cardiovascular risk factor (microalbuminuria or proteinuria, hypertension and left ventricular hypertrophy, left ventricular systolic or diastolic dysfunction, or an ankle-brachial index of less than 0.9). ${ }^{21}$ The primary outcome of the LEADER trial was MACE, defined as the composite of nonfatal MI, nonfatal stroke, or cardiovascular death. The prespecified secondary outcome included a broader definition that incorporated coronary revascularization, or hospitalization for unstable angina or heart failure. Of the patients enrolled, 7598 $(81.3 \%)$ had established cardiovascular disease. The mean duration of diabetes was 12.8 years. From a cardiovascular perspective, $31 \%$ had a history of previous 
TABLE 1. Summary of completed cardiovascular outcome trials involving DPP-4 inhibitors, GLP-1 receptor agonists, and SGLT2 inhibitors

\begin{tabular}{|c|c|c|c|c|c|}
\hline Class & Trial (n) & $\begin{array}{c}\text { Antihyperglycemic } \\
\text { agent }\end{array}$ & $\begin{array}{l}\text { Key entry criteria } \\
\text { (in addition to } \\
\text { type } 2 \text { diabetes) }\end{array}$ & $\begin{array}{c}\text { Median } \\
\text { follow-up, } \\
\mathbf{y}\end{array}$ & $\begin{array}{c}\text { Primary outcome } \\
\text { hazard ratio } \\
(95 \% \text { confidence } \\
\text { interval })\end{array}$ \\
\hline \multirow[t]{4}{*}{$\begin{array}{l}\text { DPP-4 } \\
\quad \text { inhibitors }\end{array}$} & $\begin{array}{l}\text { CARMELINA } \\
\text { (Cardiovascular and } \\
\text { Renal Microvascular } \\
\text { Outcome Study With } \\
\text { Linagliptin in Patients } \\
\text { With Type } 2 \text { Diabetes } \\
\text { Mellitus) }{ }^{14} \\
(\mathrm{n}=6979)\end{array}$ & Linagliptin & High $\mathrm{CV}$ and renal risk & 2.2 & $\begin{array}{l}\text { 3-point MACE } \\
1.02(0.89-1.17)\end{array}$ \\
\hline & $\begin{array}{l}\text { EXAMINE (Examination } \\
\text { of Cardiovascular } \\
\text { Outcomes with } \\
\text { Alogliptin versus } \\
\text { Standard of Care) })^{15} \\
(\mathrm{n}=5380)\end{array}$ & Alogliptin & $\begin{array}{l}\text { Acute coronary syndrome } \\
\text { within } 15-90 \mathrm{~d} \text { before } \\
\text { randomization }\end{array}$ & 1.5 & $\begin{array}{l}\text { 3-point MACE } \\
0.96(95 \% \text { upper } \\
\text { limit } \leq 1.16)\end{array}$ \\
\hline & $\begin{array}{l}\text { SAVOR-TIMI } 53 \text { (Does } \\
\text { Saxagliptin Reduce the } \\
\text { Risk of Cardiovascular } \\
\text { Events When Used } \\
\text { Alone or Added to Other } \\
\text { Diabetes Medications) } \\
(\mathrm{n}=16,492)\end{array}$ & Saxagliptin & $\begin{array}{l}\text { History of or multiple risk } \\
\text { factors for CVD }\end{array}$ & 2.1 & $\begin{array}{l}\text { 3-point MACE } \\
1.00(0.89-1.12)\end{array}$ \\
\hline & $\begin{array}{l}\text { TECOS (Trial Evaluating } \\
\text { Cardiovascular } \\
\text { Outcomes with } \\
\text { Sitagliptin) } \\
(\mathrm{n}=14,671)\end{array}$ & Sitagliptin & Preexisting CVD & 3.0 & $\begin{array}{l}\text { 4-point MACE } \\
0.98(0.88-1.09)\end{array}$ \\
\hline \multirow[t]{5}{*}{$\begin{array}{l}\text { GLP-1 } \\
\text { receptor } \\
\text { agonists }\end{array}$} & $\begin{array}{l}\text { ELIXA (Evaluation of } \\
\text { LIXisenatide in Acute } \\
\text { coronary syndrome) }^{18} \\
(\mathrm{n}=6068)\end{array}$ & Lixisenatide & $\begin{array}{l}\text { Acute coronary event } \\
\text { within } 180 \mathrm{~d} \text { before } \\
\text { screening }\end{array}$ & 2.1 & $\begin{array}{l}\text { 4-point MACE } \\
1.02(0.89-1.17)\end{array}$ \\
\hline & $\begin{array}{l}\text { EXSCEL (Exenatide Study } \\
\text { of Cardiovascular Event } \\
\text { Lowering Trial) })^{19} \\
(\mathrm{n}=14,752)\end{array}$ & Exenatide (once weekly) & $\begin{array}{l}\text { With or without } \\
\text { preexisting CVD }\end{array}$ & 3.2 & $\begin{array}{l}\text { 3-point MACE } \\
0.91(0.83-1.00)\end{array}$ \\
\hline & $\begin{array}{l}\text { Harmony Outcomes }{ }^{20} \\
\qquad(\mathrm{n}=9463)\end{array}$ & Albiglutide & $\begin{array}{l}\text { Established coronary, } \\
\text { cerebrovascular, or } \\
\text { peripheral artery disease }\end{array}$ & 1.5 & $\begin{array}{l}\text { 3-point MACE } \\
0.78(0.68-0.90)\end{array}$ \\
\hline & $\begin{array}{l}\text { LEADER (Liraglutide } \\
\text { Effect and Action in } \\
\text { Diabetes: Evaluation of } \\
\text { Cardiovascular } \\
\text { Outcome Results) })^{21} \\
(\mathrm{n}=9340)\end{array}$ & Liraglutide & $\begin{array}{l}\text { Preexisting CVD, renal } \\
\text { disease, or heart failure } \\
\text { at } \geq 50 \text { y old or } \geq 1 \mathrm{CV} \\
\text { risk factor at } \geq 60 \text { y old }\end{array}$ & 3.8 & $\begin{array}{l}\text { 3-point MACE } \\
0.87(0.78-0.97)\end{array}$ \\
\hline & $\begin{array}{l}\text { SUSTAIN-6 (Trial to } \\
\text { Evaluate Cardiovascular } \\
\text { and Other. Long-term } \\
\text { Outcomes with } \\
\text { Semaglutide in Subjects } \\
\text { with Type } 2 \\
\text { Diabetes)*,22 } \\
(\mathrm{n}=3297)\end{array}$ & Semaglutide & $\begin{array}{l}\text { Preexisting CVD, heart } \\
\text { failure, or CKD at } \geq 50 \text { y } \\
\text { old or } \geq 1 \mathrm{CV} \text { risk factor } \\
\text { at } \geq 60 \text { y old }\end{array}$ & 2.1 & $\begin{array}{l}\text { 3-point MACE } \\
0.74(0.58-0.95)\end{array}$ \\
\hline
\end{tabular}




\begin{tabular}{|c|c|c|c|c|c|}
\hline Class & Trial (n) & $\begin{array}{c}\text { Antihyperglycemic } \\
\text { agent }\end{array}$ & $\begin{array}{l}\text { Key entry criteria } \\
\text { (in addition to } \\
\text { type } 2 \text { diabetes) }\end{array}$ & $\begin{array}{c}\text { Median } \\
\text { follow-up, } \\
\mathbf{y}\end{array}$ & $\begin{array}{c}\text { Primary outcome } \\
\text { hazard ratio } \\
(95 \% \text { confidence } \\
\text { interval })\end{array}$ \\
\hline \multirow[t]{3}{*}{$\begin{array}{l}\text { SGLT2 } \\
\quad \text { inhibitors }\end{array}$} & $\begin{array}{l}\text { CANVAS (Canagliflozin } \\
\text { Cardiovascular } \\
\text { Assessment Study) } \\
\text { Program } \\
\quad(\mathrm{n}=10,142)\end{array}$ & Canagliflozin & $\begin{array}{l}\text { Preexisting CVD at } \geq 30 \mathrm{y} \\
\text { old or } \geq 2 \mathrm{CV} \text { risk } \\
\text { factors at } \geq 50 \mathrm{y}\end{array}$ & 2.4 & $\begin{array}{l}\text { 3-point MACE } \\
0.86(0.75-0.97)\end{array}$ \\
\hline & $\begin{array}{l}\text { DECLARE } \\
\text { (Dapagliflozin Effect } \\
\text { on Cardiovascular } \\
\text { Events)-TIMI } 58^{24} \\
(\mathrm{n}=17,160)\end{array}$ & Dapagliflozin & $\begin{array}{l}\text { Established atherosclerotic } \\
\text { CVD or multiple risk } \\
\text { factors for } \\
\text { atherosclerotic CVD }\end{array}$ & 4.2 & $\begin{array}{l}\text { 3-point MACE } \\
0.93(0.84-1.03)\end{array}$ \\
\hline & $\begin{array}{l}\text { EMPA-REG OUTCOME } \\
\text { (BI } 10773 \\
\text { [Empagliflozin] } \\
\text { Cardiovascular } \\
\text { Outcome Event Trial } \\
\text { in Type } 2 \text { Diabetes } \\
\text { Mellitus Patients) } \\
(\mathrm{n}=7020)\end{array}$ & Empagliflozin & $\begin{array}{l}\text { Preexisting CVD, } \\
\text { with BMI } \leq 45 \mathrm{~kg} / \mathrm{m}^{2} \\
\text { and eGFR } \\
\geq 30 \mathrm{~mL} / \mathrm{min} / 1.73 \mathrm{~m}^{2}\end{array}$ & 3.1 & $\begin{array}{l}\text { 3-point MACE } \\
0.86(0.74-0.99)\end{array}$ \\
\hline
\end{tabular}

$D P P-4$, Dipeptidyl peptidase-4; $C V$, cardiovascular; $C V D$, cardiovascular disease; $M A C E$, major adverse cardiovascular events; $G L P$-1, glucagon-like peptide-1; SGLT2, sodium glucose cotransporter-2; $C K D$, chronic kidney disease; $B M I$, body mass index; $e G F R$, estimated glomerular filtration rate. *Not powered to demonstrate superiority.

MI, $15 \%$ a history of stroke or transient ischemic attack, $40 \%$ had a history of previous coronary revascularization (although the distribution of percutaneous coronary intervention vs CABG surgery was not reported) and $25 \%$ a history of chronic kidney disease. In the overall trial, liraglutide was associated with a $13 \%$ relative risk reduction in MACE events (hazard ratio, 0.87; 95\% confidence interval $[\mathrm{CI}], 0.78-0.97 ; P=.01$ for superiority). Impressively, cardiovascular death was reduced by $22 \%$ in the liraglutide-assigned group versus placebo (hazard ratio, $0.78 ; 95 \% \mathrm{CI}, 0.66-0.93 ; P=.007)$. In addition, there was a reduction in all-cause mortality in the liraglutide versus placebo group by $15 \%$ (hazard ratio, $0.85 ; 95 \% \mathrm{CI}$, 0.74-0.97; $P=.02$ ). Nonfatal MI and stroke were numerically but not statistically reduced. In subsequent post hoc analyses, a benefit of liraglutide was observed in those with a history of atherosclerotic vascular disease (who did or did not have a previous ischemic event) and was particularly noteworthy in those with a history of polyvascular disease. ${ }^{35,36}$ No cardiovascular benefit was noted in those without a history of atherosclerotic vascular disease over the follow-up duration of the trial.

A recently published post hoc analysis of the LEADER trial has focused on understanding the benefits of liraglutide in patients with and without a history of chronic kidney disease (as defined as those with a baseline eGFR above or below $\left.60 \mathrm{~mL} / \mathrm{min} / 1.73 \mathrm{~m}^{2}\right){ }^{37}$ Within the trial, 2158 patients had an eGFR of less than $60 \mathrm{~mL} / \mathrm{min} / 1.73 \mathrm{~m}^{2}$, with the remaining 7182 patients having an eGFR of greater than $60 \mathrm{~mL} / \mathrm{min} / 1.73 \mathrm{~m}^{2}$. As expected, patients with type 2 diabetes and an eGFR of less than $60 \mathrm{~mL} / \mathrm{min} / 1.73 \mathrm{~m}^{2}$ had a greater placebo cardiovascular event rate (primary composite MACE outcome $21.4 \%$ vs $14.9 \%$ in those with eGFR $60 \mathrm{~mL} / \mathrm{min} / 1.73 \mathrm{~m}^{2}$ or greater). A similar step-up in event rates was observed when the group was dichotomized by evidence of micro/macroalbuminuria versus normoalbuminuria. Patients within the low eGFR stratum appeared to derive greater cardiovascular benefit from liraglutide. An impressive $31 \%$ relative risk reduction in the primary MACE outcome was observed in this group (hazard ratio, 0.69; 95\% CI, 0.57-0.85) compared with $6 \%$ in those with eGFR greater than $60 \mathrm{~mL} / \mathrm{min} / 1.73 \mathrm{~m}^{2}$ (hazard ratio, 0.95; 95\% CI, 0.83-1.07) with a statistically significant interaction between the groups $\left(P_{\text {interaction }}=.01\right)$. Greater efficacy was also observed for the expanded MACE outcome in those with low versus high eGFR $(26 \%$ vs $7 \%$, $\left.P_{\text {interaction }}=.02\right)$. Rates of all-cause mortality were approximately twice as high in those with an eGFR less than $60 \mathrm{~mL} / \mathrm{min} / 1.73 \mathrm{~m}^{2}$, and liraglutide was associated with numerically greater reduction in this outcome in this group compared with those who had an eGFR of $60 \mathrm{~mL} / \mathrm{min} / 1.73 \mathrm{~m}^{2}$ or greater. Also, the benefits of liraglutide appeared to be numerically greater in those with an eGFR less than $60 \mathrm{~mL} / \mathrm{min} / 1.73 \mathrm{~m}^{2}$ who also had a history of previous MI or stroke. Although A1C reductions were similar in both groups, there was greater reduction in body weight with liraglutide in those with 
eGFR $<60 \mathrm{~mL} / \mathrm{min} / 1.73 \mathrm{~m}^{2}$. No signals for excess side effects were observed with liraglutide based on strata of baseline eGFR.

Many mechanisms have been suggested to mediate the cardiovascular benefits of GLP-1RAs, and the readers are referred to an excellent review on this topic. ${ }^{38}$ Specifically, impact on vascular inflammation and immune modulation have been suggested to mediate the antiatherosclerotic benefits noted. The benefits are not believed to be driven by improvements in glycemia per se and are believed to be independent of body weight and blood pressure changes. ${ }^{39,40}$ We have recently reported that the benefits noted in LEADER were independent of baseline low-density lipoprotein cholesterol levels and were observed over and above the use of statin therapies, suggesting that the mechanism of benefit is distinct and complementary to lipid lowering. ${ }^{41}$

\section{WHAT ARE THE KEY TAKE-HOME MESSAGES FOR CARDIAC SURGEONS?}

Type 2 diabetes is an exceedingly common comorbidity in patients managed by cardiac surgeons, affecting upward of $35 \%$ of patients in large contemporary trials. ${ }^{42,43}$ Furthermore, since CABG is superior to percutaneous coronary intervention for diabetes patients with multivessel coronary artery disease, ${ }^{44}$ this number is only expected to increase. Cardiac surgeons must therefore be familiar with the current landscape of antihyperglycemic therapies, particularly those that have been shown to reduce cardiovascular events and mortality. We suggest the following key take-away messages for cardiac surgeons that are general to the field of diabetes pharmacotherapy and then more specific to the LEADER trial and subanalysis discussed previously:

- Cardiac surgeons should become knowledgeable about the recently completed large cardiovascular outcome trials of antihyperglycemic therapies and the change in clinical practice guidelines for these agents in people with type 2 diabetes with clinical cardiovascular disease, including a recent position paper and decision algorithm that has been endorsed by the American College of Cardiology. ${ }^{30}$

- Cardiac surgeons must be aware that 2 classes of antihyperglycemic agents, namely the SGLT2 inhibitors and the GLP-1RAs, have been prioritized in the guidelines as preferred treatments in patients with clinical cardiovascular disease, even though they are more expensive than the commonly used generic diabetes medications. Specifically, at the present time, 2 marketed GLP-1RAs, namely liraglutide and semaglutide, and 3 SGLT2 inhibitors, namely canagliflozin, dapagliflozin, and empagliflozin, have demonstrated cardiovascular superiority to placebo. Clinical practice guidelines endorse the use of empagliflozin and liraglutide and at the present time with the greatest level of recommendation, whereas newer iterations of guidelines will likely also incorporate the evidence with the other agents listed previously.

- Cardiac surgeons should develop strategies to either prescribe, collaborate with diabetes specialists/primary care physicians, and/or recommend in their discharge planning the use of these evidence-based therapies as part of the secondary prevention checklist in these patients. Although analyses specifically in patients with a history of CABG are currently available only for empagliflozin, all the trials have included a large proportion of patients with a history of previous CABG.

- In the LEADER trial, liraglutide was associated with a marked reduction in MACE, with a $22 \%$ reduction in cardiovascular death and a $15 \%$ reduction in all-cause mortality. These benefits were observed on top of standard of care. Furthermore, the benefits of therapy are greater in those with an eGFR less than $60 \mathrm{~mL} / \mathrm{min} / 1.73 \mathrm{~m}^{2}$ as shown in the subanalysis of LEADER, and as we have shown, appear to be restricted to those with documented atherosclerotic cardiovascular disease with or without a history of a previous ischemic event.

- Neither GLP1RAs nor SGLT2 inhibitors are associated with hypoglycemia but can potentiate hypoglycemia when combined with a sulfonylurea or insulin.

- Liraglutide is generally well tolerated, and the most common side effect is transient nausea, which is often self-limiting. The agent is usually prescribed at a dose of $0.6 \mathrm{mg}$ daily for 1 week, followed by $1.2 \mathrm{mg}$ daily for 1 week and then $1.8 \mathrm{mg}$ daily thereafter, and is administered subcutaneously by the patients. The agent can be used down to an eGFR of $15 \mathrm{~mL} / \mathrm{min} / 1.73 \mathrm{~m}^{2}$. Weight reduction and small decreases in blood pressure are observed. ${ }^{45}$

- Empagliflozin (and other SGLT2 inhibitors), are also well tolerated, with the most common side effects including genital infections. ${ }^{46}$ Rare complications include diabetic ketoacidosis that can be precipitated by metabolic stress. Therefore, therapy should be withheld 3 days before cardiac surgery and should be avoided in patients with type 1 diabetes, and on sick days. Hypovolemia-related side effects can also occur, and therefore we do not suggest using this therapy in those with systolic blood pressure of $<100 \mathrm{~mm} \mathrm{Hg}$. Like liraglutide, weight and blood pressure reduction are observed. The current renal indications for SGLT2 inhibitors vary based on the country and the specific agent, but SGLT2 inhibitors are generally not recommended at an eGFR of less than 45 to $60 \mathrm{~mL} / \mathrm{min} / 1.73 \mathrm{~m}^{2}$. This is not due to renal toxicity, 
but rather because glycemic efficacy declines as renal filtration decreases.

- Although both GLP-1RAs and SGLT2 inhibitors reduce cardiovascular events, the former is associated with greater benefit on ischemic outcomes and the latter with greater benefit on heart failure.

- GLP-1RAs and SGLT2i are being studied in patients without diabetes in large outcome studies evaluating atherosclerotic events, renal outcomes, and heart failure treatment.

\section{Conflict of Interest Statement}

Dr Verma holds a Tier 1 Canada Research Chair in Cardiovascular Surgery; reports receiving research grants and/or speaking honoraria from Amgen, AstraZeneca, Bayer HealthCare, Boehringer Ingelheim, Eli Lilly, Janssen, Merck, Novartis, Novo Nordisk, Sanofi, Servier, and Valeant; and is the President of the Canadian Medical and Surgical Knowledge Translation Research Group, a federally incorporated not-for-profit physician organization. Dr Leiter reports receiving research grants and/or honoraria from AstraZeneca, Boehringer Ingelheim, Eli Lilly, GlaxoSmithKline, Janssen, Merck, Novo Nordisk, Sanofi, and Servier; and being a Steering Committee member of the LEADER trial. Dr Bhatt discloses the following relationships-Advisory Board: Cardax, Elsevier Practice Update Cardiology, Medscape Cardiology, Regado Biosciences; Board of Directors: Boston VA Research Institute, Society of Cardiovascular Patient Care, TobeSoft; Chair: American Heart Association Quality Oversight Committee; Data Monitoring Committees: Baim Institute for Clinical Research (formerly Harvard Clinical Research Institute, for the PORTICO trial, funded by St. Jude Medical, now Abbott), Cleveland Clinic (including for the ExCEED trial, funded by Edwards), Duke Clinical Research Institute, Mayo Clinic, Mount Sinai School of Medicine (for the ENVISAGE trial, funded by DaiichiSankyo), Population Health Research Institute; Honoraria: American College of Cardiology (Senior Associate Editor, Clinical Trials and News, ACC.org; Vice-Chair, ACC Accreditation Committee), Baim Institute for Clinical Research (formerly Harvard Clinical Research Institute; RE-DUAL PCI clinical trial steering committee funded by Boehringer Ingelheim), Belvoir Publications (Editor in Chief, Harvard Heart Letter), Duke Clinical Research Institute (clinical trial steering committees), HMP Global (Editor in Chief, Journal of Invasive Cardiology), Journal of the American College of Cardiology (Guest Editor; Associate Editor), Population Health Research Institute (for the COMPASS operations committee, publications committee, steering committee, and USA national co-leader, funded by Bayer), Slack Publications (Chief Medical Editor, Cardiology Today's Intervention), Society of Cardiovascular Patient Care (Secretary/Treasurer),
WebMD (CME steering committees); Other: Clinical Cardiology (Deputy Editor), NCDR-ACTION Registry Steering Committee (Chair), VA CART Research and Publications Committee (Chair); Research Funding: Abbott, Amarin, Amgen, AstraZeneca, Bayer, Boehringer Ingelheim, Bristol-Myers Squibb, Chiesi, Eisai, Ethicon, Forest Laboratories, Idorsia, Ironwood, Ischemix, Lilly, Medtronic, PhaseBio, Pfizer, Regeneron, Roche, Sanofi Aventis, Synaptic, The Medicines Company; Royalties: Elsevier (Editor, Cardiovascular Intervention: A Companion to Braunwald's Heart Disease); Site Co-Investigator: Biotronik, Boston Scientific, St Jude Medical (now Abbott), Svelte; Trustee: American College of Cardiology; Unfunded Research: FlowCo, Fractyl, Merck, Novo Nordisk, PLx Pharma, Takeda. All other authors have nothing to disclose with regard to commercial support.

The authors thank Hwee Teoh, $\mathrm{PhD}$, of the Divisions of Endocrinology and Metabolism, and Cardiac Surgery at the Li Ka Shing Knowledge Institute of St Michael's Hospital for editorial support in the preparation of this manuscript.

\section{References}

1. International Diabetes Federation, ed. IDF Diabetes Atlas. 8th ed. Brussels, Belgium: International Diabetes Federation; 2017.

2. Verma S, Juni P, Mazer CD. Pump, pipes, and filter: do SGLT2 inhibitors cover it all? Lancet. 2019;393:3-5.

3. Rawshani A, Rawshani A, Franzén S, Eliasson B, Svensson AM, Miftaraj M, et al. Mortality and cardiovascular disease in type 1 and type 2 diabetes. N Engl J Med. 2017;376:1407-18.

4. Gregg EW, Li Y, Wang J, Burrows NR, Ali MK, Rolka D, et al. Changes in diabetes-related complications in the United States, 1990-2010. N Engl J Med. 2014;370:1514-23

5. Verma S, Mazer CD, Bhatt DL. The perils of polyvascular disease in type 2 diabetes. Lancet Diabetes Endocrinol. 2018;6:914-6.

6. Bonaca MP, Gutierrez JA, Cannon C, Giugliano R, Blazing M, Park JG, et al. Polyvascular disease, type 2 diabetes, and long-term vascular risk: a secondary analysis of the IMPROVE-IT trial. Lancet Diabetes Endocrinol. 2018;6:934-43.

7. Farkouh ME, Verma S. Prevention of heart failure with SGLT-2 inhibition: insights from CVD-REAL. J Am Coll Cardiol. 2018;71:2507-10.

8. Echouffo-Tcheugui JB, Xu H, DeVore AD, Schulte PJ, Butler J, Yancy CW, et al. Temporal trends and factors associated with diabetes mellitus among patients hospitalized with heart failure: findings from Get with the Guidelines-Heart Failure registry. Am Heart J. 2016;182:9-20.

9. Scirica BM, Mosenzon O, Bhatt DL, Udell JA, Steg PG, McGuire DK, et al. Cardiovascular outcomes according to urinary albumin and kidney disease in patients with type 2 diabetes at high cardiovascular risk: observations from the SAVOR-TIMI 53 trial. JAMA Cardiol. 2018;3:155-63.

10. Braunwald E. Heart failure. JACC Heart Fail. 2013;1:1-20.

11. US Food and Drug Administration Center for Drug Evaluation and Research. Guidance for Industry. In: US Department of Health and Human Services, ed. Diabetes Mellitus-Evaluating Cardiovascular Risk in New Antidiabetic Therapies to Treat Type 2 Diabetes. Silver Spring, MD: U.S. Department of Health and Human Services; 2008.

12. Nissen SE, Wolski K. Effect of rosiglitazone on the risk of myocardial infarction and death from cardiovascular causes. N Engl J Med. 2007;356:2457-71.

13. Control Group, Turnbull FM, Abraira C, Anderson RJ, Byington RP, Chalmers JP, et al. Intensive glucose control and macrovascular outcomes in type 2 diabetes. Diabetologia. 2009;52:2288-98.

14. Rosenstock J, Perkovic V, Johansen OE, Cooper ME, Kahn SE, Marx N, et al. Effect of linagliptin vs placebo on major cardiovascular events in adults with type 2 diabetes and high cardiovascular and renal risk: the CARMELINA randomized clinical trial. JAMA. 2019;321:69-79. 
15. White WB, Cannon CP, Heller SR, Nissen SE, Bergenstal RM, Bakris GL, et al. Alogliptin after acute coronary syndrome in patients with type 2 diabetes. $N$ Engl J Med. 2013;369:1327-35.

16. Scirica BM, Bhatt DL, Braunwald E, Steg PG, Davidson J, Hirshberg B, et al. Saxagliptin and cardiovascular outcomes in patients with type 2 diabetes mellitus. N Engl J Med. 2013;369:1317-26.

17. Green JB, Bethel MA, Armstrong PW, Buse JB, Engel SS, Garg J, et al. Effect of sitagliptin on cardiovascular outcomes in type 2 diabetes. N Engl J Med. 2015; 373:232-42.

18. Pfeffer MA, Claggett B, Diaz R, Dickstein K, Gerstein HC, Køber LV, et al. Lixisenatide in patients with type 2 diabetes and acute coronary syndrome. N Engl J Med. 2015;373:2247-57.

19. Holman RR, Bethel MA, Mentz RJ, Thompson VP, Lokhnygina Y, Buse JB, et al. Effects of once-weekly exenatide on cardiovascular outcomes in type 2 diabetes. N Engl J Med. 2017;377:1228-39.

20. Hernandez AF, Green JB, Janmohamed S, D'Agostino RB Sr, Granger CB, Jones NP, et al. Albiglutide and cardiovascular outcomes in patients with type 2 diabetes and cardiovascular disease (Harmony Outcomes): a double-blind, randomised placebo-controlled trial. Lancet. 2018;392:1519-29.

21. Marso SP, Daniels GH, Brown-Frandsen K, Kristensen P, Mann JF, Nauck MA, et al. Liraglutide and cardiovascular outcomes in type 2 diabetes. $N$ Engl J Med. 2016;375:311-22.

22. Marso SP, Bain SC, Consoli A, Eliaschewitz FG, Jódar E, Leiter LA, et al. Semaglutide and cardiovascular outcomes in patients with type 2 diabetes. $N$ Engl J Med. 2016;375:1834-44.

23. Neal B, Perkovic V, Mahaffey KW, de Zeeuw D, Fulcher G, Erondu N, et al. Canagliflozin and cardiovascular and renal events in type 2 diabetes. $N$ Engl J Med. 2017:377:644-57.

24. Wiviott SD, Raz I, Bonaca MP, Mosenzon O, Kato ET, Cahn A, et al. Dapagliflozin and cardiovascular outcomes in type 2 diabetes. $N$ Engl $\mathrm{J}$ Med. 2019;380:347-57.

25. Zinman B, Wanner C, Lachin JM, Fitchett D, Bluhmki E, Hantel S, et al Empagliflozin, cardiovascular outcomes, and mortality in type 2 diabetes. N Engl J Med. 2015;373:2117-28.

26. Zelniker TA, Wiviott SD, Raz I, Im K, Goodrich EL, Bonaca MP, et al. SGLT2 inhibitors for primary and secondary prevention of cardiovascular and renal outcomes in type 2 diabetes: a systematic review and meta-analysis of cardiovascular outcome trials. Lancet. 2019;393:31-9.

27. Verma S, Mazer CD, Al-Omran M, Inzucchi SE, Fitchett D, Hehnke U, et al. Cardiovascular outcomes and safety of empagliflozin in patients with type 2 diabetes mellitus and peripheral artery disease: a subanalysis of EMPA-REG OUTCOME. Circulation. 2018;137:405-7.

28. Verma S, Mazer CD, Fitchett D, Inzucchi SE, Pfarr E, George JT, et al. Empagliflozin reduces cardiovascular events, mortality and renal events in participants with type 2 diabetes after coronary artery bypass graft surgery: subanalysis of the EMPA-REG OUTCOME(R) randomised trial. Diabetologia. 2018;61: $1712-23$.

29. Davies MJ, D'Alessio DA, Fradkin J, Kernan WN, Mathieu C, Mingrone G, et al. Management of hyperglycemia in type 2 diabetes, 2018. A consensus report by the American Diabetes Association (ADA) and the European Association for the Study of Diabetes (EASD). Diabetes Care. 2018;41:2669-701.

30. Das SR, Everett BM, Birtcher KK, Brown JM, Cefalu WT, Januzzi JL, et al. 2018 ACC Expert Consensus Decision Pathway on novel therapies for cardiovascular risk reduction in patients with type 2 diabetes and atherosclerotic cardiovascular disease: a report of the American College of Cardiology Task Force on Expert Consensus Decision Pathways. J Am Coll Cardiol. 2018;72: $3200-23$.
31. Byrne NJ, Parajuli N, Levasseur JL, Boisvenue J, Beker DL, Masson G, et al. Empagliflozin prevents worsening of cardiac function in an experimental model of pressure overload-induced heart failure. JACC Basic Transl Sci. 2017;2:347-54.

32. Verma S, Rawat S, Ho KL, Wagg CS, Zhang L, Teoh H, et al. Empagliflozin increases cardiac energy production in diabetes: novel translational insights into the heart failure benefits of SGLT2 inhibitors. JACC Basic Transl Sci. 2018;3:575-87.

33. Verma S, Mazer CD, Yan AT, Mason T, Slabiak A, Benga OO, et al. EMPA-HEART Cardiolink-6 trial: a randomized trial evaluating the effect of empagliflozin on left ventricular structure, function and biomarkers in people with type 2 diabetes (T2D) and coronary heart disease. American Heart Association Scientific Sessions 2019; 2018; Chicago, Ill.

34. Bethel MA, Patel RA, Merrill P, Lokhnygina Y, Buse JB, Mentz RJ, et al. Cardiovascular outcomes with glucagon-like peptide-1 receptor agonists in patients with type 2 diabetes: a meta-analysis. Lancet Diabetes Endocrinol. 2018;6: $105-13$

35. Verma S, Bhatt DL, Bain SC, Buse JB, Mann JFE, Marso SP, et al. Effect of liraglutide on cardiovascular events in patients with type 2 diabetes mellitus and polyvascular disease: results of the LEADER trial. Circulation. 2018;137: 2179-83.

36. Verma S, Poulter NR, Bhatt DL, Bain SC, Buse JB, Leiter LA, et al. Effects of liraglutide on cardiovascular outcomes in patients with type 2 diabetes mellitus with or without history of myocardial infarction or stroke. Circulation. 2018; 138:2884-94.

37. Mann JFE, Fonseca V, Mosenzon O, Raz I, Goldman B, Idorn T, et al. Effects of liraglutide versus placebo on cardiovascular events in patients with type 2 diabetes mellitus and chronic kidney disease. Circulation. 2018;138:2908-18.

38. Drucker DJ. The cardiovascular biology of glucagon-like peptide-1. Cell Metab. $2016 ; 24: 15-30$

39. Verma S, Bain SC, Bhatt DL, Leiter LA, Mazer CD, McGuire DK, et al. The glucagon-like peptide-1 receptor agonists liraglutide and semaglutide improve cardiovascular and renal outcomes across most body mass index categories in type 2 diabetes: results of the LEADER and SUSTAIN 6 trials. Circulation. 2018;138:A14806.

40. Leiter LA, Bain SC, Bhatt DL, Buse J, Mazer CD, Pratley R, et al. The glucagon-like peptide-1 receptor agonists liraglutide and semaglutide improve cardiovascular and renal outcomes across baseline blood pressure categories: analysis of LEADER and SUSTAIN 6. Circulation. 2018;138:A15707.

41. Verma S, Leiter LA, Mazer CD, Bain SC, Buse J, Marso S, et al. Liraglutide reduces cardiovascular events and mortality in type 2 diabetes mellitus independently of baseline low-density lipoprotein cholesterol levels and statin use. Circulation. 2018;138:1605-7.

42. Mazer CD, Whitlock RP, Fergusson DA, Hall J, Belley-Cote E, Connolly K, et al. Restrictive or liberal red-cell transfusion for cardiac surgery. N Engl J Med. 2017; 377:2133-44.

43. Zenati MA, Bhatt DL, Bakaeen FG, Stock EM, Biswas K, Gaziano JM, et al. Randomized trial of endoscopic or open vein-graft harvesting for coronary-artery bypass. N Engl J Med. 2019;380:132-41.

44. Verma S, Farkouh ME, Yanagawa B, Fitchett DH, Ahsan MR, Ruel M, et al. Comparison of coronary artery bypass surgery and percutaneous coronary intervention in patients with diabetes: a meta-analysis of randomised controlled trials. Lancet Diabetes Endocrinol. 2013;1:317-28.

45. Lingvay I, Leiter LA. Use of GLP-1 RAs in cardiovascular disease prevention: a practical guide. Circulation. 2018;137:2200-2.

46. Cherney DZ, Udell JA. Use of sodium glucose cotransporter 2 inhibitors in the hands of cardiologists: with great power comes great responsibility. Circulation. 2016;134:1915-7. 